Int. J. Dev. Biol. 58: 613-622 (2014)

doi: $10.1387 / \mathrm{ijdb} .140081 \mathrm{cb}$

\title{
An immunocytochemical window into the development of Platynereis massiliensis (Annelida, Nereididae)
}

\author{
CONRAD HELM ${ }^{1}$, HELGE ADAMO ${ }^{1}$, STEPHANE HOURDEZ ${ }^{2,3}$ and CHRISTOPH BLEIDORN ${ }^{*, 1}$ \\ ${ }^{1}$ Molecular Evolution and Systematics of Animals, Institute of Biology, University of Leipzig, Leipzig, Germany, \\ ${ }^{2}$ CNRS, Equipe ABICE, UMR7144, Station Biologique de Roscoff, and \\ ${ }^{3}$ UPMC Université Paris 06, Equipe ABICE, UMR7144, Station Biologique de Roscoff, Roscoff, France
}

\begin{abstract}
The nereidid annelid Platynereis dumerilii emerged as a well-understood model organism. $P$. dumerilii and $P$ massiliensis are sister taxa, which are morphologically indistinguishable as adults. Interestingly, they exhibit highly contrasting life-histories: while $P$. dumeriliiis a gonochorostic species with planktonic feeding larvae, $P$ massiliensis is a protandric hermaphrodite with lecitotrophic semi-direct -development in brood tubes. Using light microscopy and immunohistochemical methods coupled with confocal laser scanning microscopy, we describe the development of $P$ massiliensis. Musculature was stained with phalloidin-rhodamine. FMRFamide, acetylated $\alpha$-tubulin, and serotonin were targeted by antibodies for the staining of neuronal structures. Additionally, eye development was investigated with the specific $22 \mathrm{C} 10$-antibody. The development of $P$. massiliensis is characterized by the absence of a free-swimming stage, a late development of food uptake, and the presence of a large amount of yolk even in late juvenile stages. Most notably, early juvenile stages already exhibit an organization of several organ systems that resembles those of adults. Larval characters present in the free-swimming feeding larvae of $\boldsymbol{P}$. dumerilii, as e.g. the apical organ and larval eyes, are absent and regarded to be lost in developing stages of $P$. massiliensis. Many of the differences found in the development of these two species can be described in the context of heterochronic changes. We strongly advocate expanding evolutionary developmental studies from the well-established model annelid $\boldsymbol{P}$. dumerilii to the closely related $\boldsymbol{P}$ massiliensis to study the evolutionary conservation and divergence of genetic pathways involved in developmental processes.
\end{abstract}

KEY WORDS: cLSM, evodevo, eye development, heterochrony, model organism, polychaete

The vast majority of bilaterian animals are classified into three large clades: Deuterostomia, Ecdysozoa and Lophotrochozoa. Whereas several animal model systems for evolutionary developmental research are well established for the former two taxa, lophotrochozoans are underrepresented in this regard (GIGA Community of Scientists, 2014). However, especially in the last decade the annelid Platynereis dumerilii emerged as a well-understood model species (Fischer and Dorresteijn, 2004; Fischer et al., 2010; Simakov et al., 2013). Consequently, techniques as whole mount in situ hybridization, cell ablation, RNAinterference, and morpholino knockdowns are well established (Tessmar-Raible and Arendt, 2003; Veedin-Rajan et al., 2013). Moreover, transgenic lineages have been created (Backfisch et al., 2013) and a genome sequencing project is underway for this species (http://4dx.embl.de/platy/). Evolutionary developmental studies on Platynereis dumerilii provided important insights into the evolution of segmentation, vision and the nervous system in Bilateria (Prud'homme et al., 2003; Arendt et al., 2004; Denes et al., 2007; Tessmar-Raible et al., 2007; Jekely et al., 2008; Dray et al., 2010; Tomer et al., 2010).

Platynereis dumeriliiis a marine annelid of the family Nereididae, which are part of the Errantia (Struck et al., 2011; Weigert et al., in press). The life cycle is well established and controlled in the lab and this gonochoric species has an indirect development, with planktotrophic larvae (Fischer and Dorresteijn, 2004). Interestingly, with Platynereis massiliensis the closest relative of this species is a sympatrically distributed, semi-direct developing, protandric species (Pfannenstiel et al., 1987; Schneider et al., 1992). Using a comparative approach this situation sets up a system where

Abbreviations used in this paper: FMRFamide, Phe-Met-Arg-Phe amide; LIR, -like immunoreactivity.

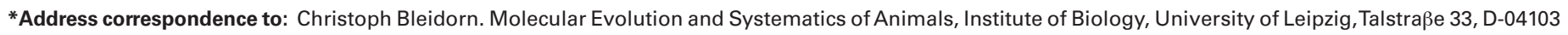
Leipzig, Germany. E-mail: bleidorn@uni-leipzig.de
}

Accepted: 20 June 2014.

ISSN: Online 1696-3547, Print 0214-6282 
phylogenetic constraints could be disentangled from life-history constraints when investigating character evolution and gene expression patterns in these sister taxa.

Recent studies have also emphasized the importance of heterochronic changes to understand the evolution of larval diversity in annelids. Heterochrony describes the shift in the timing of developmental events or the expression of phenotypic traits (Gould, 1977). For example, it has been shown that a delayed offset of larval traits is found when planktotrophic and adelphotrophic offspring in the same species of spionids are compared (Gibson and Gibson, 2004). Heterochronic shifts have also been reported by comparison of the development of other closely related annelids (Pernet and McHugh, 2010; Helm et al., 2013). In the case of Platynereis, a comparison of $P$. dumerilii and $P$. massiliensis would be ideal to describe and understand temporal shifts leading to different early development styles and morphology.

Here we describe the semi-direct development of Platynereis massiliensis using immunohistochemical methods and subsequent confocal laser scanning microscopy to characterize muscular and nervous system development. Using 22C10-antibody staining, we furthermore visualize the pattern of immunoreactivity of this sensory photoreceptor cell marker in different developmental stages. By comparing the development of $P$. massiliensis and $P$. dumerilii we are able to describe changes in the timing of events in musculature, nervous system and eye development.

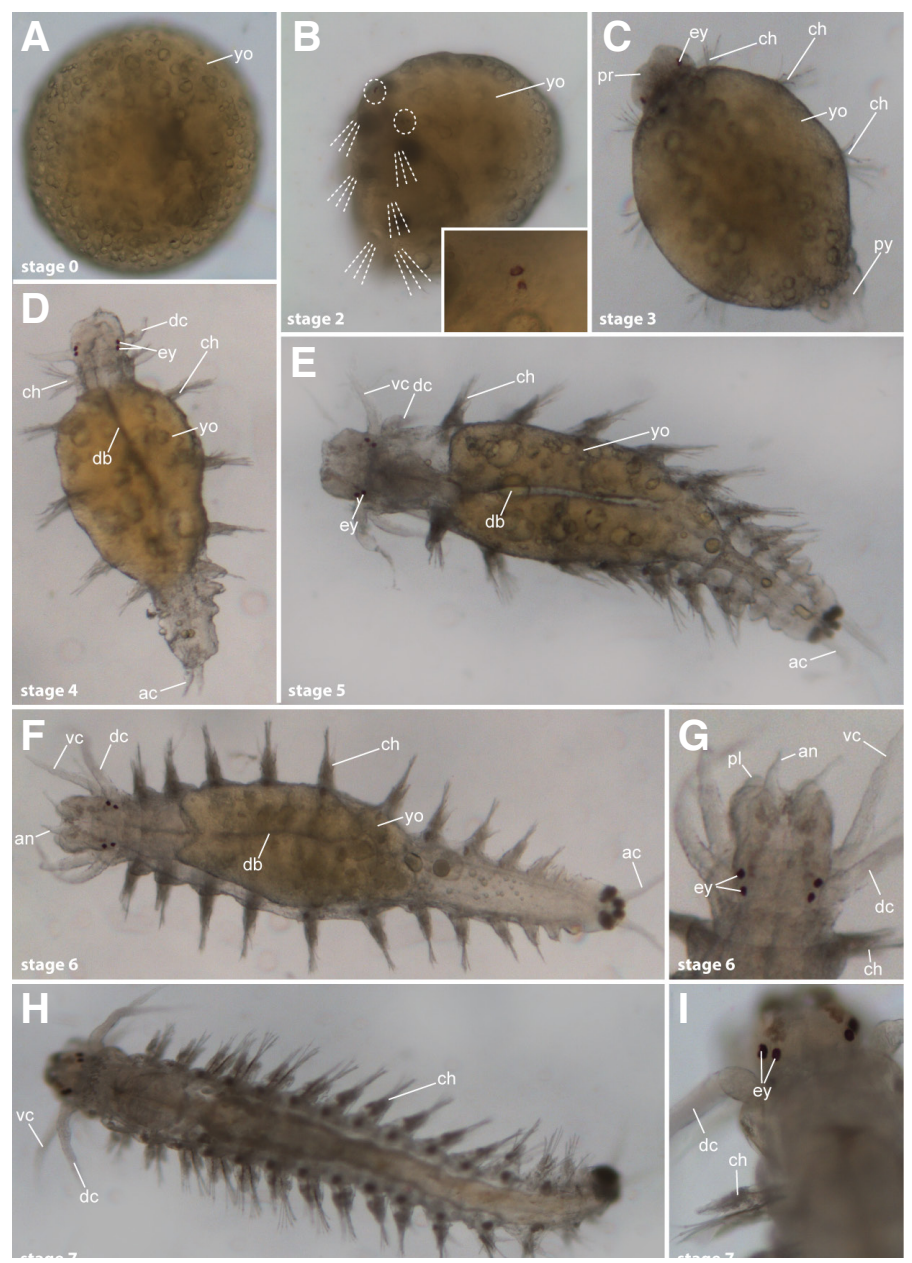

\section{Results}

\section{General development of Platynereis massiliensis}

Because of the unknown duration since fertilization, we established a staging system for the juveniles according to morphological characteristics (number of chaetigers, body shape, etc.): stage 0: spherical, prototroch developed, rich in yolk, no visible chaetigers

stage 1: 3 chaetigers, spherical, rich in yolk, remnants of prototroch visible

stage 2: 3 chaetigers, very large amount of yolk at the vegetal pole, spherical, absence of prototroch

stage 3: 3 chaetigers, elliptic body shape, development of mouth opening

stage 4: 3-5 chaetigers, yolk almost consumed, antennae start to develop

stage 5: 5-8 chaetigers, antennae and palps fully developed stage 6: 8-11 chaetigers, adult body shape

stage 7: 11-15 chaetigers, adult body shape

Early developmental stages (stage 0 ) of $P$. massiliensis are characterized by a spherical shape and richness in yolk (Fig.1A). At stage 1 (not shown) and 2 the juveniles are still rich in yolk and spherical, but two pairs of eyespots and 3 pairs of chaetigers are developed (Fig.1B). The anterior and the posterior ends are formed. Stage 3 develops a distinct prostomial and pygidial regions, clearly separated from the trunk that remains ovoid (Fig. 1C). Stage 3 exhibits 3 pairs of chaetigerous segments, and additional segments develop at the posterior end, leading to stage 4 (Fig. 1D). At this stage 3-5 chaetigers are visible, and a pair of anterior dorsal cirri and anal cirri is formed. In addition the dorsal blood vessel is detectable. Stage 5 exhibits 5-8 chaetigers (Fig. $1 \mathrm{E})$. The dorsal and ventral cirri of the first chaetiger become prominent (tentacular cirri), the chaetae of this segment do not develop further, and the dorsal blood vessel forms a distinct structure. Additionally, the adult antennae start to develop. Individuals

Fig. 1. General development of Platynereis massiliensis illustrated by light microscopic images. Anterior is up in $A-D, G$ and I, and left in $E, F$ and $H$. All stages are in dorsal view, except of $B$, where the lateral side is shown. (A) Stage 0 specimens with a spherical shape and a very large amount of yolk (yo). (B) Stage 2 specimens with 3 pairs of developing chaetigers and two pairs of eye-spots (dotted circles) (see insert for a detailed view). (C) Stage 3 specimens elongate in shape and develop a distinct prostomium (pr) and pygidium (py). Three pairs of chaetigers (ch) and two pairs of eye-spots (ey) are also present. (D) Specimens at stage 4 exhibit 3-5 chaetigers (ch) and the dorsal cirri (dc) start to grow. Notably the anal cirri (ac) and the dorsal blood vessel (db) are visible. (E) At stage 5 the individuals continue elongation and bear up to 8 chaetigerous segments (ch). The ventral (vc) and dorsal anterior cirri (dc) are fully developed and the dorsal blood vessel (db) is represented as a distinct structure. Notably remnants of yolk (yo) are still present within the trunk. (F) Stage 6 specimens are characterized by the presence of up to 11 chaetigerous segments (ch) and one pair of anterior antennae (an). Remnants of yolk (yo) are still present. (G) Stage 6 exhibits distinct palps (pl), antennae (an), and the ventral (vc) and dorsal cirri (dc) are present. (H) Specimens at stage 7 exhibit adult body organization. They do not possess yolk anymore, and more than 11 chaetigers are developed. At this developmental stage the individuals leave the parental brood tube and start living autonomously. (I) Detailed view of the anterior body showing distinct eye-spots (ey) and the dorsal cirri (dc). 
at this stage and stage 6 still have remnants of yolk within the trunk (Fig. 1F). At stage 6, adult antennae and adult palps are formed (Figs. $1 \mathrm{~F}, \mathrm{G}$ ). The body shape is elongated and 8-11 chaetigerous segments are formed. In stage-7 specimens, the body shape resembles those of adults (Figs. $1 \mathrm{H}, \mathrm{I}$ ). Antennae, palps, anterior and anal cirri are fully developed, and no remnants of yolk are present but the characteristic color now lines the whole length of the digestive tube. At this stage the juveniles start feeding and leave the parental brood tube.

\section{Development of the body musculature}

At early developmental stages (stage 0) the f-actin fibers are restricted to the region of the blastodisc containing micromeres and to filaments between the macromeres at the vegetal pole (Fig. 2A). Initially, specimens at early stage 1 bear distinct muscular bundles (Fig. 2B). Antero-posterior directed longitudinal muscles are developed at the animal pole. Notably, a prominent median muscle bundle is detectable. The protostomial region of stage 1 is formed by distinct muscle fibers, and 3 pairs of parapodial muscles are present (Fig. 2B). Circular muscle fibers appear at stage 2, growing from ventro-median regions towards the sides of the embryo. The longitudinal muscles form distinct bundles framing the median muscle fibers, and other laterally arranged longitudinal fibers spread towards dorsal parts (Fig. $2 \mathrm{C}$ ), whereas the vegetal pole of the embryo exhibits no muscular fibers. At stage 3, the musculature additionally covers the dorsal part of the embryo (Fig. 2D). At this stage the amount of yolk at the vegetal (dorsal) pole is reduced and the longitudinal muscle fibers formerly found in lateral regions are shifted dorsally, representing a dense layer. Circular muscle fibers grow towards the dorsal side (Fig. 2D, inset). Ventrally, prominent longitudinal muscle bundles, the median muscle bundle and serial circular muscle fibers are detectable. The 3 pairs of parapodial muscle fibers continue their growth. A densely stained region in the anterior part corresponds to the developing eversible proboscis, the additional segments formed posteriorly do not exhibit any signs of parapodial muscles (Fig. 2D). Parapodial muscle fibers appear in these segments at stage 4 (Fig. 2E). The whole body is elongated and pharyngeal musculature and muscle fibers forming the palps are visible. Additionally, longitudinal and circular muscle bundles are thickened and the parapodial musculature of the first 3 segments resembles those of adult worms (Fig. 2E). The proboscis is still developing anteriorly and forms a densely stained oval structure. Later stages exhibit an elongated body (Fig. 2F), and 2 ventral bundles of longitudinal muscles, a dense layer of dorsal longitudinal muscle fibers forming a dorsal plate, and well-developed parapodial musculature are visible. The outer muscular layer is formed by semicircular fibers located dorsally and the formerly prominent median muscle is hardly detectable (Fig. 2F). From this stage individuals increase in body size and segment number, but the muscular organization remains resembling the adult condition.
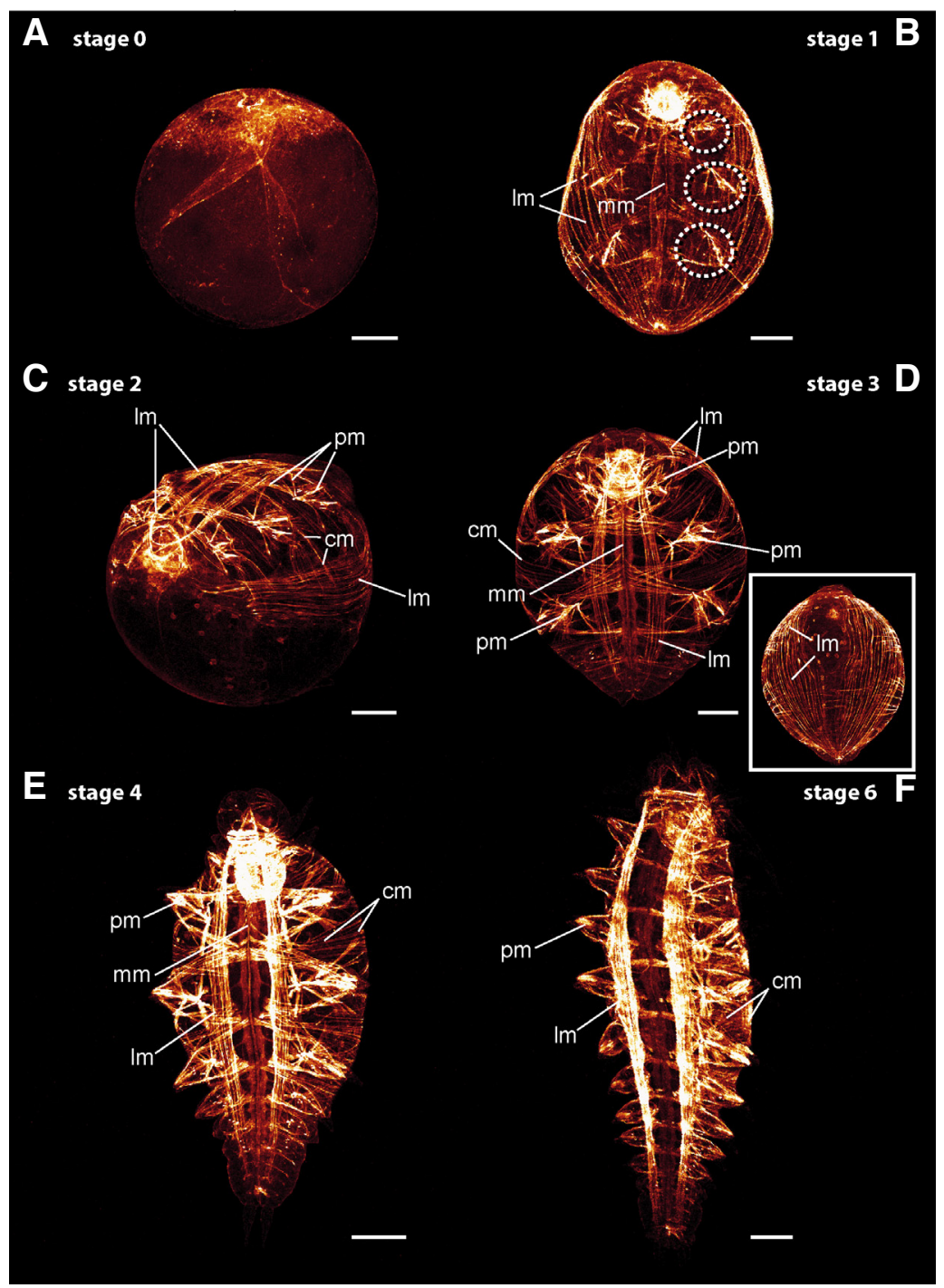

Fig. 2. Confocal maximum projections of the myogenesis in Platynereis massiliensis revealed by phalloidin-rhodamine staining. Anterior is up in $B, D-F$, and left in $B$ and $C$. All stages are in ventral view, except of $A$ and $C$ where the ventral side is up. (A) Stage O larva with the animal pole containing the blastodisc up. Only few F-actin fibers between the macromeres are stained at the vegetal pole. (B) The larva at stage 1 develops 3 pairs of parapodial appendages (dotted circles) and distinct median ( $\mathrm{mm}$ ) and lateral longitudinal muscle fibers (Im). (C) In larvae at stage 2, the ventral longitudinal muscles $(\mathrm{Im})$ represent distinct bundles and the lateral longitudinal muscles (Im) are well-developed. Notably, the first circular muscle fibers $(\mathrm{cm})$ and further parapodial muscles (pm) are formed. (D) Later larvae of stage 3 possess serially-arranged ventral circular muscle fibers $(\mathrm{cm})$, well-developed parapodial musculature (pm) and distinct ventral longitudinal muscle bundles (Im). Interestingly, the longitudinal muscle bundles (Im) formerly located laterally now form two prominent longitudinal dorsal muscle layers (insert). Posteriorly, additional segments start to develop. (E) Stage 4 larvae exhibit 3-5 chaetigerous segments with well-developed parapodial musculature $(\mathrm{pm})$. The circular muscle fibers $(\mathrm{cm})$ run from the ventral larval body towards the posterior end, forming a semicircular muscle layer. The longitudinal muscle fibers $(\mathrm{Im})$ are restricted to the median muscle bundle $(\mathrm{mm})$, and two ventral and two dorsal muscle bundles. (F) Stage 6 larvae exhibit 7-10 chaetigerous segments with well-developed parapodial muscle fibers. Now the larval body exhibits the muscular conditions also known for adult specimens. cm, circular muscle fibers, Im, longitudinal muscle fibers; mm, median muscle bundle; pm, parapodial muscle fibers; dotted circle, developing parapodial muscles. Scale bar, $100 \mu \mathrm{m}$ 
Fig. 3. Confocal maximum projections of the FMRFamide-LIR (red) and acetylated- $\alpha$-tubulin-IR (blue) in Platynereis massiliensis. Anterior is up in all images. All stages are in ventral view, except of $A$ and $B$ that show a frontal (A) and lateral view (B). (A) Stage 0 only exhibits a prominent staining of cilia (ci) in the equatorial midline. No staining of neuronal structures is detectable. (B) Atstage 1, the ciliation (ci) is still present. The first tubulinergic structures of the nervous system are also stained. The ventral nerve cord (vn), distinct circumesophageal connectives (cc) and the brain (br) are also stained. (C) Stage 2 specimens beara 3 segmental nervous system organization according to the $\alpha$-tubulin immunoreactivity. Notably 3 pairs of parapodial nerves (pn), the ventral nerve cord (vn) and the circumesophageal connectives (cc) are stained. Notably, the first FMRFamide-LIR is visible in the subesophageal ganglion (sg) and within one soma at the apex of the parapodial nerves (arrow head). (D) At stage 3, the specimens exhibit prominent FMRFamidergic somata (arrowheads) and distinct parapodial nerves (pn) in the 3 chaetigers (see insert for details). Notably one pair of FMRFamidergic somata is visible in each ganglion (gn) located in proximity to the branching parapodial nerves (pn). Furthermore the brain (br) is well developed (see insert for details) and exhibits tubulin-LIR and FMRFamide-LIR. (E) Stage 4 bears neuronal innervation within the developing anterior (ci) and anal cirri (ac), and the palps (pl). Notably the parapodium is branching into the ventral neuropodium (ne) and the dorsal notopodium (no), each of them exhibiting distinct FMRFamide-LIR (arrow heads) (see insert for details). Additionally, the ventral nerve cord exhibits FMRFamidergic immunoreactivity within ganglion neurons (gn) (see insert for details). (F) Stage 6 bears prominent neuronal innervation in the antennae (an), the palps (pl) and the anterior cirri (ci). Furthermore, the neuro- (ne) and notopodia (no) possess FMRFamide-LIR (arrow heads) (see insert for details). Notably, the ganglia of the ventral nerve cord (vn) show different FMRFamide-LIR according to their position within the antero-posterior body axis. Anterior ganglia within the first to chaetigerous segments exhibit ganglia consisting of 3 anterior and 3 posterior FMRFamidergic somata. Posterior ganglia behind the first two chaetigerous segments solely exhibit two anterior and 3 posterior neurons (gn) exhibiting immunoreactivity (see insert for details). ac, anal cirri; br, brain; cc, circumesophageal connective; ci, cirri; gn, soma within the ganglion; ne, neuropodium; no, noto-

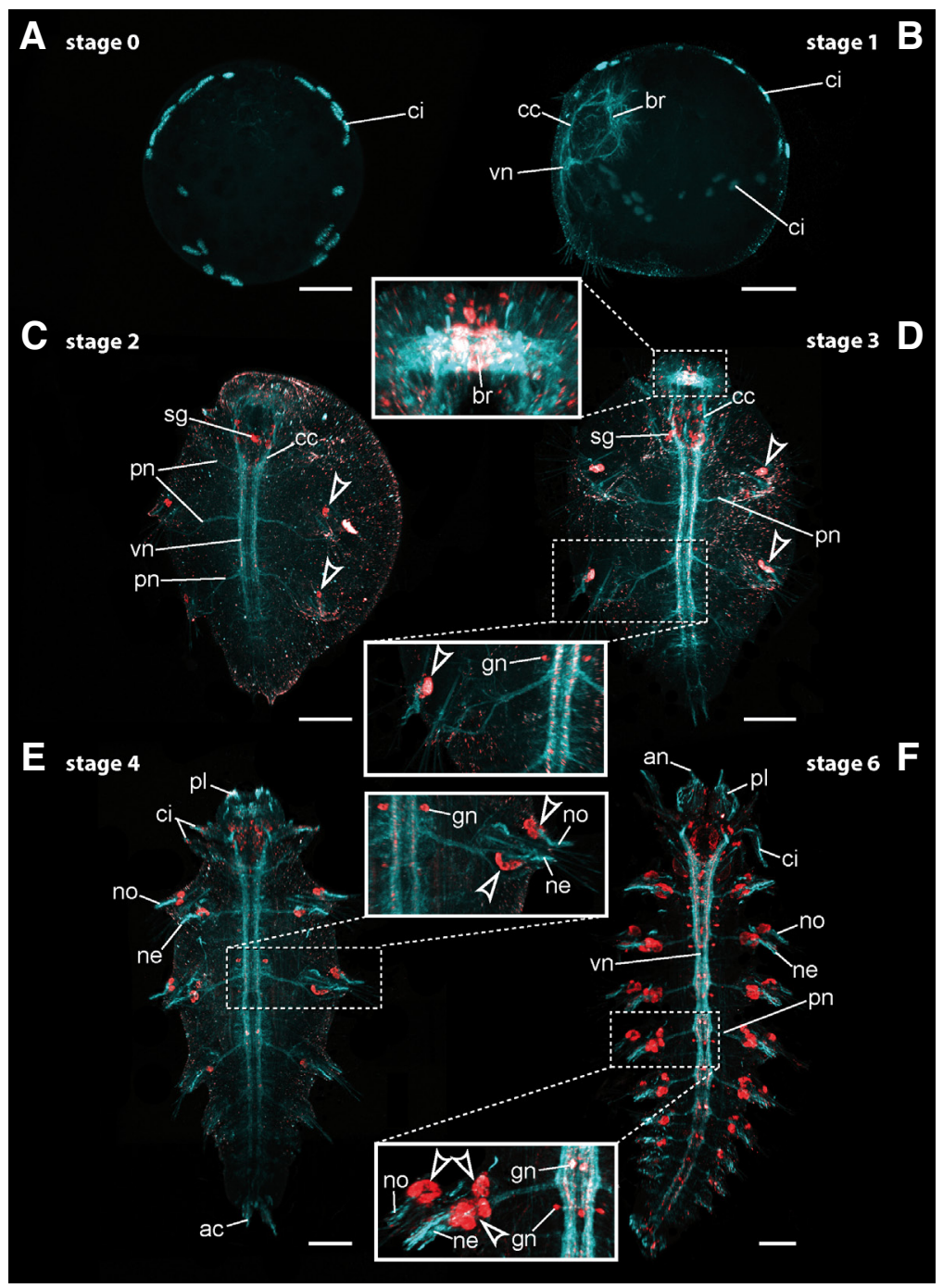
podium; pn, parapodial nerve; pl, palps; vn, sg, subesophageal ganglion; ventral nerve cord; arrow heads, FMRFamidergic somata. Scale bars, 50 um.

\section{Anti- $\alpha$-tubulin staining}

No distinct anti- $\alpha$-tubulin staining of neuronal structures is visible at stage 0 (Fig. 3A). Nevertheless, the ciliation of the prototrochal ciliary band exhibits tubulin-immunoreactivity forming patches of cilia encircling the early embryo (Fig. 3A). Prototrochal remnants are present at stage 1 as well (Fig. 3B). In addition, a distinct staining of the tubulinergic nervous system becomes obvious at the animal pole (Fig. 3B). At this stage a staining of the circumesophageal connectives, lateral head nerves and the brain region are present. The ventral nerve cord is also detectable (not shown). At stage 2, the pattern of the tubulinergic staining resembles that of the previous stage. In stage-3 embryos, a well-developed brain, distinct circumesophageal connectives, a ventral nerve cord formed by two distinct nerve bundles that grow towards the posterior end, and an increasing number of nerve fibers innervating parapodial and protostomial regions is exhibited (Fig. 3D). The tubulinergic nervous system of stage 4 embryos exhibits a similar staining as at the previous stage. However, an increase of fibers innervating the protostomial regions including the palps and the antennae is visible. At stages 5 and 6 , the tubulinergic pattern is similar to that described for stage 4 (Fig. 3F).

FMRFamide-LIR in different larval stages of $\mathrm{P}$. massiliensis

FMRFamide-Like ImmunoReactivity (LIR) cannot be found before stage 2 . This signal is visible in distinct somata surrounding the developing mouth opening, within the subesophageal ganglion. Additional staining is restricted to one cell located at the base of the second and third parapodia (Fig. 3C). In stage-3 embryos, the brain exhibits additional FMRFamide-LIR, revealing somata forming a distinct cluster of cells (Fig. 3D). The number of stained somata around the mouth opening increases. At stage 4, individuals exhibit at least two distinct FMRFamidergic somata in the second and third pair of parapodia. Each is restricted to either the noto- or neuropodial branch (Fig 3E). Only one parapodial branch bearing a FMRFamidergic soma is detectable in the fourth parapodium. Notably, the first parapodium also bears a single parapodial branch, which lacks a prominent FMRFamide-LIR. The first FMRFamide-LIR restricted to distinct somata of ventral nerve cord appears at stage 4 (Fig. 3E). In each segment, two somata are visible anterior and three posterior to the parapodial nerve. Ad- 
ditionally, the number of FMRFamidergic somata surrounding the mouth opening and the circumesophageal connectives increases. At stage 6, distinct FMRFamide-LIR is visible, with older segments showing at least 4 prominent somata located within the parapodia (Fig. 3F). Ontogenetic younger segments bear fewer stained cells. The FMRFamide-LIR in the head region increases in number of stained somata. FMRFamidergic somata of the ventral nerve cord are not arranged in distinct ganglia in this stage. Instead, both ganglionic regions seem to be fused and exhibit equally distributed somata (Fig. 3F). Furthermore, distinct immunoreactivity is present in the region of the posterior growth zone. At all stages, the FMRFamidergic somata of the first chaetiger are less developed than those of the following segments.

\section{Serotonin-LIR in different larval stages of P. massiliensis}

In early stages, serotonin-like immunoreactivity (LIR) is not detectable (Fig. 4A). At stage 1, the first serotonergic somata are present (Fig. 4B). Two cell clusters underlying the eye-spots, and 2 single somata showing serotonin-LIR are located at the anterior end of the vegetal pole. Although, 3 segments and their corresponding parapodia are developed, serotonin-LIR is not detectable in other body regions. A distinct larval brain region, lateral circumesophageal connectives around the forming mouth opening and ventral nerve fibers representing the ventral nerve cord including several somata are visible in stage 2 embryos (Fig. 4C). Notably, the serotonergic somata of the ventral nerve cord are arranged in distinct clusters. The single soma firstly visible in stage-1 embryos represents part of the subesophageal ganglion in this stage (Fig. 4C). At stage 3, these serotonergic structures including the clustered arrangement of the ventral serotonergic somata become more distinct (Fig. 4D). The serotonin-LIR of the brain increases and the cell clusters close to the pigmented

Fig. 4. Confocal maximum projections of the serotonin-LIR in Platynereis massiliensis. Anterior is up in all images, except of $B$ where dorsal is up. All stages are in ventral view, except for $B$, which is in frontal view. (A) Early stage 0 specimens do not exhibit any serotonin-LIR. (B) At stage 1, the first immunoreactive cells are detectable anteriorly in the form of two brambleshaped cell clusters and a pair of ventral individual somata. (C) At stage 2, the serotonin-LIR increased. A distinct brain (br), circumesophageal connectives (cc) and the ventral nerve cord (vn) are visible. The bramble-shaped cell clusters are still present anterior to the brain. Notably, a single cell body is detectable between the bramble-shaped clusters (arrow head), and the pair of single somata is part of the subesophageal ganglion $(\mathrm{sg})$ now. (D) At stage 3, a similar pattern of serotonin-LIR like in the previous stage is visible. Only additional somata in the ventral nerve cord and in the brain (br) are stained. (E) Stage 4 exhibits distinct serotonergic ganglia (dotted circles), and a prominent staining of the subesophageal ganglion (sg). (F) At stage 7, additional segments with ventral serotonin-LIR are developed, and the subesophageal ganglion (sg) is still recognizable. Notably, the lateral parts of the protostomial palps (pl) and the posterior growth zone (pg) exhibit distinct patterns of autofluorescence (see insert for details). br, brain; cc, circumesophageal connectives; pa, parapodium; pg, posterior growth zone; pl, palps; sg, subesophageal ganglion; vn, ventral nerve cord; arrow head, single anterior cell; dotted circles, ganglia of the ventral nerve cord (vn). Scale bars, $100 \mu \mathrm{m}$. eye spots are still present. At stage 4 , an increasing serotonin-LIR is detectable in the circumesophageal connectives and ventral nerve cord. Additional signal is detectable in the posterior growth zone (Fig. 4E). Further antero-ventral nerve fibers and somata are formed within the ventral cord and the subesophageal ganglion. Investigated specimens exhibit no Serotonin-LIR in the brain and the bramble-shaped anterior cell clusters (Fig. 4E). Serotonin-LIR is present in the subesophageal ganglion at stage 7 (Fig. 4F). A prominent staining in the developing palps (see insert of Fig. 4F) and in the posterior growth zone (Fig. 4F) have to be considered as an autofluorescent signal of glandular structures.

\section{Developmental pattern of 22C10-immunoreactivity}

The mouse monoclonal antibody $22 \mathrm{C} 10$ stains the sensory photoreceptor cells in different developmental stages of the annelid Capitella teleta (Yamaguchi and Seaver, 2013) and sensory neurons and the developing eye disc within different developmental stages of Drosophila melanogaster (Hummel et al., 2000; Fujita et al., 1982). Here we tested the immunoreactivity of this antibody in different developmental stages of Platynereis massiliensis.

The first immunoreactive stainings of 22C10 are detectable in

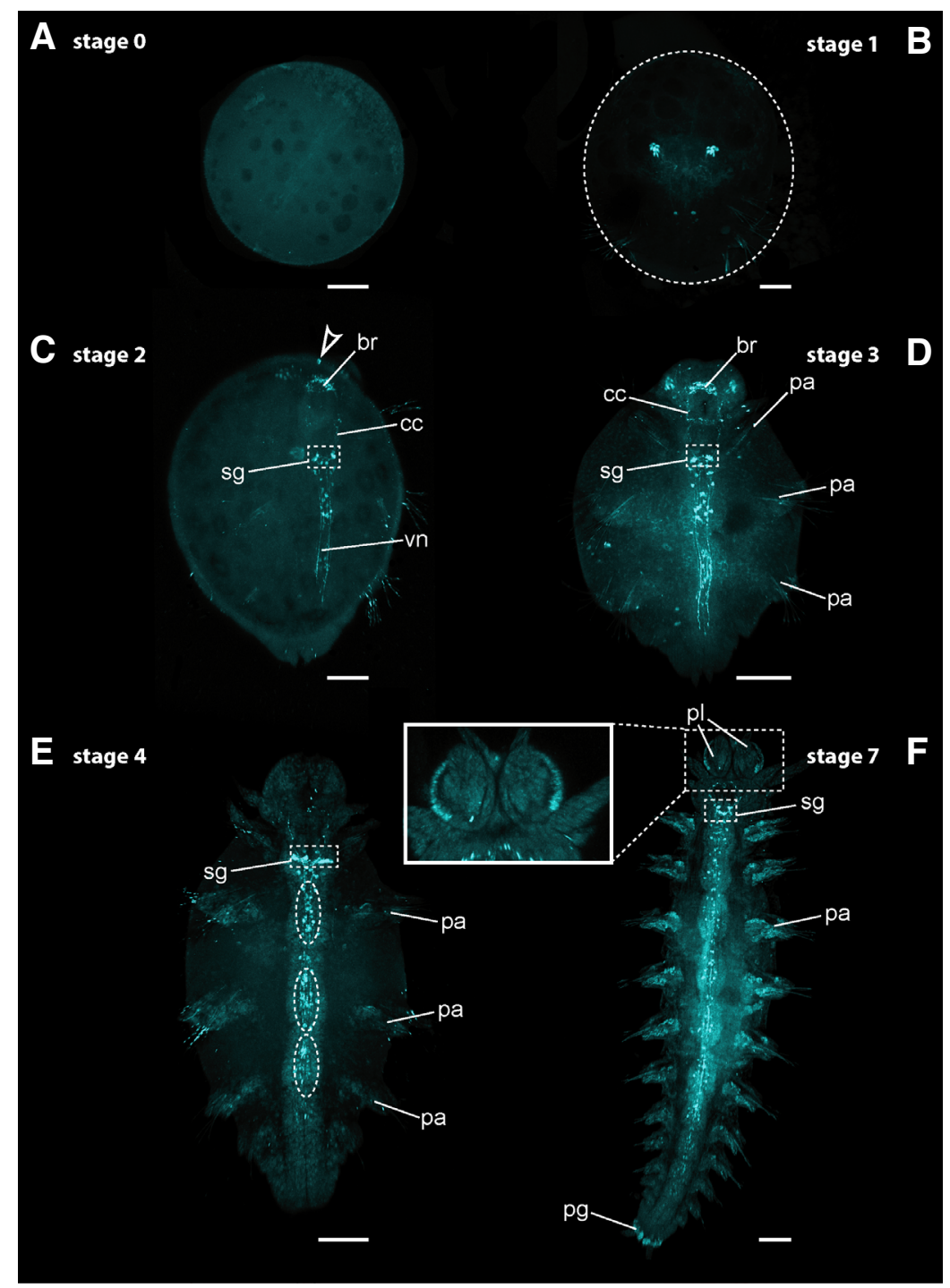



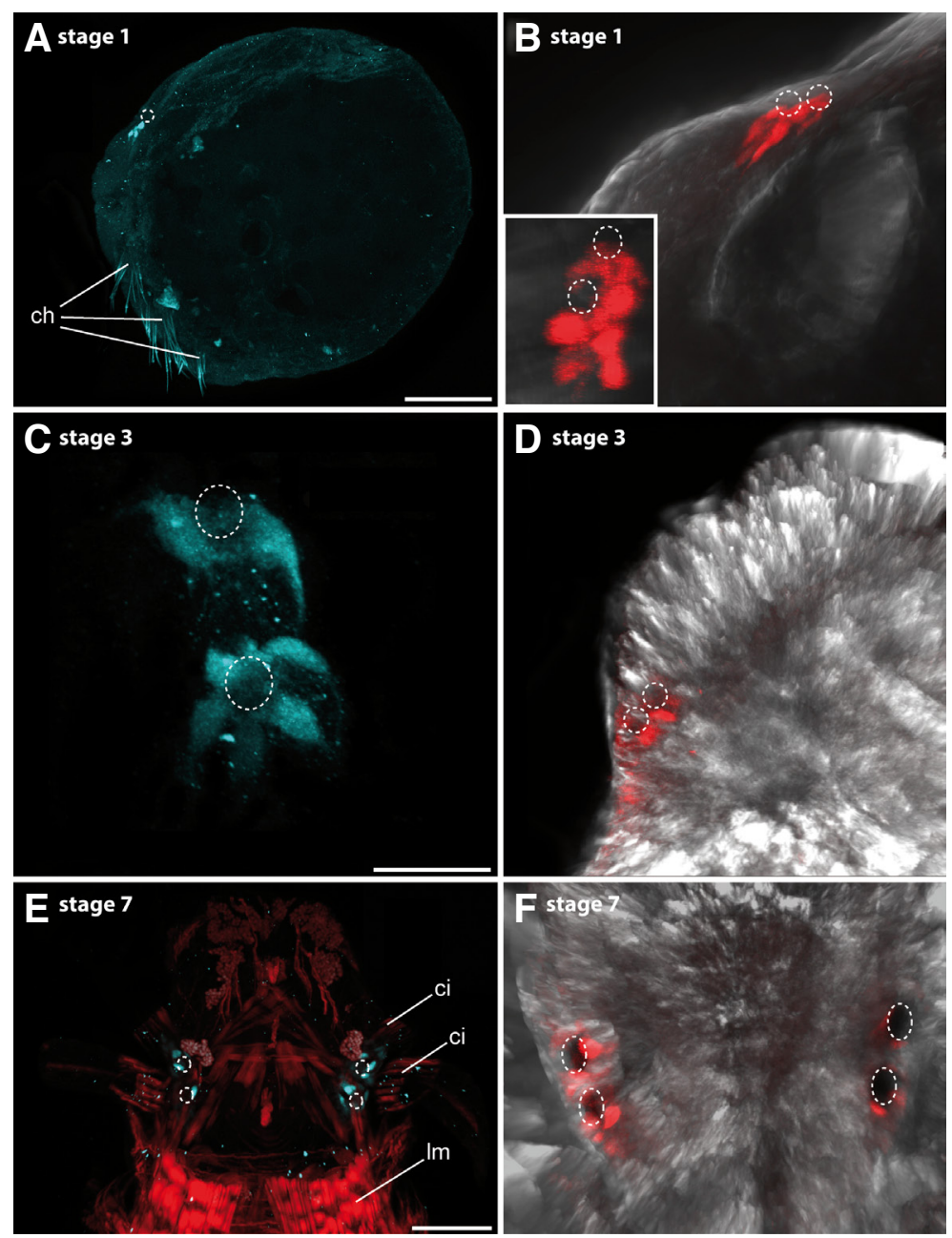

Fig. 5. Confocal maximum projections of the 22C10 immunoreactivity (blue in A, C, E and red in B, D, F), phalloidin-rhodamine staining (red in E) and differential interference contrast (DIC) images (B, D, F) of the anterior end of Platynereis massiliensis. Anterior is left in A-C and up in D-F. The specimens are in lateral (A-C) and dorsal view (D-F). (A) Early stage 1 specimens exhibit distinct immunoreactive cells at the anterior end (dotted circle). (B) Stage 1 possesses distinct immunoreactive cell clusters underlying the two lateral pigmented eyespots (dotted circles). The insert shows the cell clusters in frontal view. (C) Stage 3 exhibits two pairs of distinct 22C10-immunoreactive cell clusters underlying the pigmented eye-spots (dotted circles). (D) General view of the localization of stained cells in the anterior end of a stage 3 specimen. (E) Stage 7 exhibits two prominent eye spots (dotted circles) in close proximity to the anterior cirri (ci). Each eye spot (dotted circles) has its own cluster of associated immunoreactive somata. (F) General view of the localization of stained cells in the anterior end of a stage 7. ch, chaetae, ci, cirri; Im, longitudinal muscle bundle; dotted circles, pigmented eye-spots. Scale bars: $100 \mu \mathrm{m}$ in (A), $20 \mu \mathrm{m}$ in (C), and $50 \mu \mathrm{m}$ in (E).

stage-1 embryos (Figs. 5 A,B). At this stage, two pigmented eyespots are visible (Fig. 1B) and two distinct cell clusters are stained at the anterior pole (Figs. $5 \mathrm{~A}, \mathrm{~B}$ ). Lying in close proximity to the pigmented eye-spot, the exact number of somata is not detectable. At later stages (only stage 3 is shown), two pigmented eye-spots are present (Figs. 5 C,D), each surrounded by up to 6 stained cell bodies (Fig. 5C). The same arrangement is found at stage 7 (Fig. $5 \mathrm{E}, \mathrm{F})$. All examined stages possess two pairs of eye-spots with an underlying cluster of somata showing 22C10-immunoreactivity.

\section{Discussion}

Platynereis massiliensis was once considered as an atokous form of $P$. dumerilii and it was Hauenschild (1951) who clearly demonstrated the validity of these two species. While $P$. dumerilii has planktotrophic larvae, $P$. massiliensis is a semi-direct developer and juveniles develop within a brood tube (Pfannenstiel et al., 1987). P. dumerilii exhibits free-swimming early feeding larvae with a small amount of yolk at early stages (Fischer et al., 2010). On the contrary, $P$. massiliensis is characterized by the absence of a freeswimming stage, a late development of food uptake, and the presence of a large amount of yolk even at late juvenile stages (Hauenschild, 1951; Schneider et al., 1992). Not surprisingly, the comparison of early neuronal and muscular development reveals several differences between these species. As such, we find no evidence for the presence of an apical organ, a meta- or telotroch or larval eyes in the earliest investigated stages. Solely, the sparse ciliary distribution of these embryos can be interpreted as remnants of the prototroch. Interestingly, in $P$. dumerilii larval settlement is regulated by a myoinhibitory neuropeptide (MIP) receptor-ligand pair that is expressed in the larval apical organ and neighboring cells (Conzelmann et al., 2013).

The first evidence of a nervous system can be found in stage-1 $P$. massiliensis (see Fig. 6). This stage bears three chaetigers and can be compared to the late metatrochophora or early nectochaeta of $P$. dumerilii (see Fischer et al., 2010). Typical larval features that are assumed to be part of the annelid ground pattern, e.g., a serotonergic nerve ring underlying the prototroch (McDougall et al., 2006; Wanninger 2009), are lacking in P. massiliensis and other lecithotrophic larvae (see Winchel et al., 2010) but can be found in P. dumerilii (Fischer et al., 2010). The same is true for serotonin and FMRFamide like-immunoreactivity in the apical organ (see Fig. 6). Whereas $P$. massiliensis only exhibits remnants of apical immunoreactivity and no apical tuft, a well-developed apical organ with serotonergic and FMRFamidergic immunoreactivity can be found in various planktotrophic annelid larvae (e.g., McDougall et al., 2006; Brinkmann and Wanninger, 2008; Helm et al., 2013). Furthermore, the serotonergic and FMRFamidergic immunoreactivity in $P$. massiliensis only originates in anterior regions. For $P$. dumerilii and most other annelid larvae, the origin of FMRFamidergic immunoreactivity is described to appear at the anterior pole, whereas serotonin immunoreactivity can be found first at the posterior pole (Voronezhskaya et al., 2003; Orrhage and Müller, 2005; Wanninger et al., 2005; McDougall et al., 2006; Brinkmann and Wanninger, 2008; Kristof et al., 2008; Fischer et al., 2010; Helm et al., 2013;).

Similarly, the serotonergic immunoreactivity is detectable first in the episphere in sabellariids, spirorbiids, and sipunculans (Hessling and Westheide, 1999; Wanninger et al., 2005; Brinkmann and Wanninger, 2008; Kristof et al., 2008). The development of larval features of body musculature are also lacking for $P$. massiliensis. While most annelid larvae (including $P$. dumerili) develop 4-8 longitudinal muscle fibers at first that later develop into distinct muscular bundles of the adult body musculature (e.g., McDougall et al., 2006; Brinkmann and Wanninger, 2010; Fischer et al., 2010; Helm et al., 2013), P. massiliensis exhibits well developed 
adult-like median, ventro-lateral and dorsal longitudinal muscle bundles. The same is true for the parapodial muscle fibers, which are formed in early stages of the P. massilienis development (see Fig. 6). Furthermore, the first circular fibers in $P$. massiliensis are formed simultaneously in early stages (see Fig. 6). The same situation was described for several species of Sipuncula (Wanninger et al., 2005; Schulze and Rice, 2009; Kristof et al., 2011). In most other annelids, the circular muscle fibers appear in an anteroposterior direction, which might represent the ground pattern of muscle formation in annelid trochophores (Seaver et al., 2005; Bergter and Paululat, 2007; Bergter et al., 2008; Wanninger, 2009; Helm et al., 2013). Summarizing, we find that the nervous system and the body musculature of this stage already resemble that of

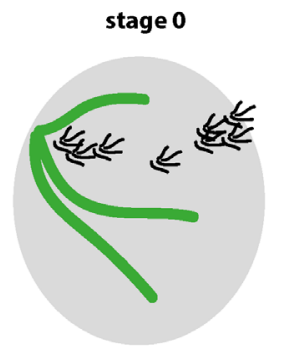

stage 3
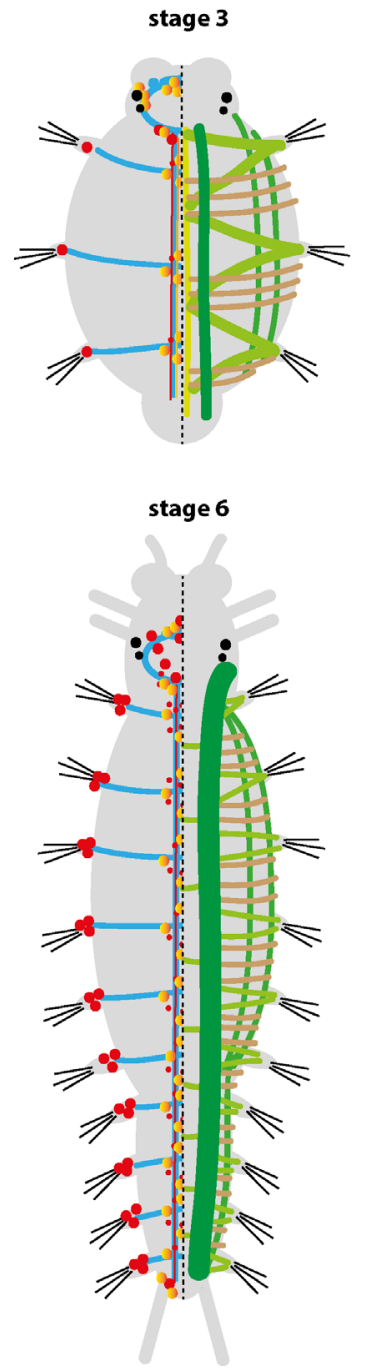

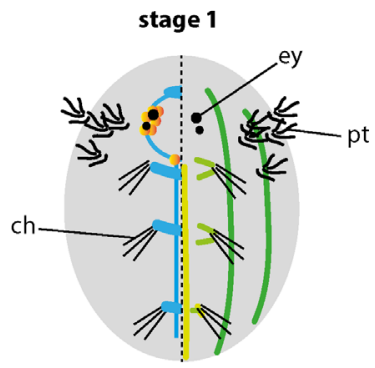

stage 4

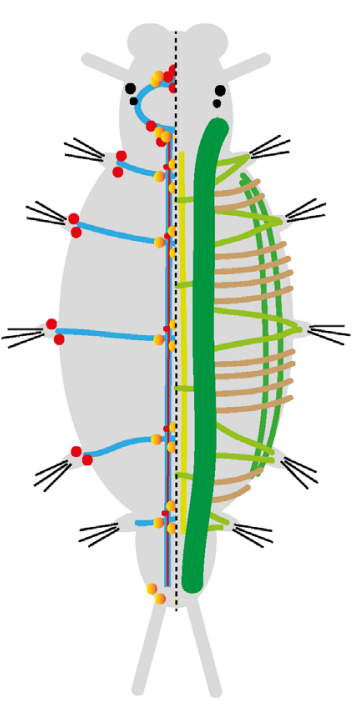

adult individuals in terms of complexity. As such, a distinct brain, circum-esophageal connectives, a ventral nerve cord, parapodial nerves, and distinct circular and longitudinal muscle bundles, as well as the parapodial musculature are fully formed in these early stages of $P$. massiliensis (Fig. 6). These conditions resemble the morphology of $P$. dumerilii shortly before metamorphosis (Fischer et al., 2010, Steinmetz et al., 2011).

In annelids, larvae usually exhibit a pair of single eyes consisting of one pigment cell and one photoreceptor cell, whereas most adults of Phyllodocida and Eunicida (including Nereididae) possess two pairs of so-called cerebral eyes (Purschke, 2005; Purschke et al., 2006). The ontogenetic studies on the presence of pigment cells and the staining with the $22 \mathrm{C} 10$ antibody support the presence of two adult-like eyes even in early juveniles of $P$. massiliensis. Notably, the general arrangement of the pigmented eye-spots in two pairs and the pattern of 22C10 - immunoreactivity remained unchanged between early and late juvenile worms. In P. dumerilii early larvae exhibit paired larval eyes with only one pigment cell and one photoreceptor cell (Rhode, 1992). Deviating from the larval eye ultrastructure and gene expression pattern (Arendt and Wittbrodt, 2001; Arendt et al., 2002), the adult eyes in $P$. dumerilii develop later in ontogenesis and are detectable earliest in the metatrochophore by the presence of two pairs of pigmented eye spots (Dorresteijn, 2005; Fischer et al., 2010). After development of adult eyes the larval eyes disappear (Arendt et al., 2002; Fischer et al., 2010). Because there are no remnants of single larval eyes and related 22C10-positive cells detectable in $P$. massiliensis, the loss of these structures has to be assumed.

In general the development of $P$. massiliensis is comparable to that of other errant annelids with lecithotrophic development stages, e.g., Neanthes arenaceodentata (Winchell et al., 2010) or Mooreonuphis stigmatis (Budaeva and Fauchald, 2010). All three species bear late feeding, not free-swimming juveniles with reduced ciliary bands, a large amount of yolk, and the presence of three chaetigers in early stages. The development of early neuronal structures exhibits remarkable similarities between Neanthes arenaceodentata and P. massiliensis. Direct-developing or semi-direct developing juveniles of both taxa seem to have lost typical larval characters, and exhibit a nervous system organization that corresponds to that of adults. As such their development can be described as tubulinergic immunoreactivity FMRFamide like-immunoreactivity serotonin like-immunoreactivity

longitudinal muscle fibers parapodial muscle fibers median muscle bundle circular muscle fibers
Fig. 6. Patterns of myogenesis and neurogenesis in different stages of Platynereis massiliensis. Schematic representation, anterior is up in all images. Diagrams are in ventral view, except of stage 0 which is in lateral view. The position of the dorsal eyes is shown for orientation. In each stage, nervous system development is shown on the left side and developmental patterns of the musculature are shown on the right side of the diagram. The black dotted line indicates the sagittal axis. Note that the major types of neuronal and muscular structures are color-coded and soley a coarse schema is represented. In later developmental stages no fundamental changes in neuronal or muscular patterns occur. ey, eye spots; ch, chaetae; pt, prototroch. 
gradual, therefore lacking a clear metamorphosis. This kind of "slow development" where many juvenile and adult structures develop simultaneously has also been reported in other annelids, and in molluscs (Page, 2009; Yamaguchi and Seaver, 2013). Interestingly, the evolutionary transition from planktonic feeding larvae to nonfeeding direct or semi-direct developing juveniles has been reported as convergent events for many other taxa as well (Collins, 2004; Raff, 2008). The comparison of the two Platynereis species shows that differences in development can be described by the timing of the on- and offset of specific morphological characters. Indeed, adult characteristics regarding the organization of the musculature and the nervous system, as well as adult eyes, appear early in development. In contrast, transitional larval characters present in $P$. dumeriliiseem to be lost in P. massiliensis (e.g., apical organ, larval eyes). Future studies focusing of the underlying expression patterns of genes involved in the timing of the formation of these characters will help to understand the genetic mechanisms underlying heterochrony (see also Smith, 2003; Winchell et al., 2010). Besides genes traditionally targeted in evolutionary developmental studies, microRNAs might be particularly important to understand the genetic bases of heterochronic shifts (Moss, 2007). MicroRNAs are short non-coding RNAs involved in the regulation of gene-expression, and their impact on the developmental timing is well understood, in particular thanks to investigations in Caenorhabditis elegans (Pasquinelli and Ruvkun, 2002). A possible role for microRNAs to create heterochronic patterns is stage-specific repression of cell fate regulators (Moss, 2007). The microRNA let-7 is supposed to play an important role in the developmental timing of various animals (Pasquinelli et al., 2000; Tennessen and Thunnel, 2007). Interestingly, Christodoulou et al., (2010) report a late onset of this gene in Platynereis dumerilii, and suggest a role in developmental transitions (i.e. metamorphosis). However, functional studies need to confirm this hypothesis. Obviously, comparative investigation of expression of this microRNA (and other selected target genes) during development in $P$. massiliensis should be envisioned in the future.

Expansion of genomic and evolutionary developmental studies to closely related species of well-established model taxa has been shown to be highly informative. Good examples come from the fruit fly Drosophila melanogasterand the soil nematode Caenorhabditis elegans, for which genomes of phylogenetically closely related species are available (Stein et al., 2003; Drosophila 12 Genomes Consortium, 2007). For instance, comparative studies of C. elegans and $C$. briggsae have revealed that differences in developmental mechanisms do not always lead to differences in morphology (Sharanya et al., 2012). We strongly advocate to complement developmental studies of the now well-established model annelid $P$. dumerilii with similar studies on its sister taxon $P$. massiliensis. This gives the opportunity for comparative evolutionary developmental studies by the adaptation of available genetic tools for $P$. dumerilii to study the evolutionary conservation and divergence of genetic pathways involved in developmental processes.

\section{Material and Methods}

\section{Animal collection and maintenance}

Tubes of $P$. massiliensis Moquin-Tandon 1869 (Nereididae, Annelida) containing adults, eggs and postembryonic juveniles were collected in Roscoff (France) in June 2012. As P. massiliensis develops without a metamorphosis, we will refer to developing stages as either embryonic or juveniles, but avoid the term larvae (see also Nielsen, 2009; Winchell et al., 2010). However, the definition of the term "larva" remains debated and alternative terminologies exist (e.g., McEdward and Janies, 1993; Pechenik, 1999).

Different stages were fixed with 4\% PFA (paraformaldehyde) in $0.1 \mathrm{M}$ PBS (phosphate buffered saline) for $3 \mathrm{hr}$. Afterwards, specimens were washed for at least $3 \mathrm{hr}$ in $0.1 \mathrm{M}$ PBS and stored in $0.1 \mathrm{M}$ PBS including $0.05 \% \mathrm{NaN}_{3}$ at $4^{\circ} \mathrm{C}$ until usage.

\section{Immunocytochemistry}

For subsequent investigations 5-6 specimens of the different developmental stages were used for each staining method. The different stainings exhibited similar results in each investigated specimen. For f-actin staining, the specimens were washed in 0.1 M PBS and subsequently incubated in a solution containing phalloidin-rhodamine $(5 \mathrm{ml}$ methanolic stock solution in $500 \mathrm{ml}$ PBS) (Invitrogen, Darmstadt, Germany). After incubation overnight at room temperature, individuals were rinsed in several changes of $0.1 \mathrm{M}$ PBS within $3 \mathrm{hr}$ and mounted between 2 glass slides in Vectashield mounting medium (Vector Laboratories, Inc., Burlingame, CA, USA).

Antibody staining was preceded by tissue permeabilization for $1 \mathrm{hr}$ in $0.1 \mathrm{M}$ PBS containing $0.1 \% \mathrm{NaN}_{3}$ and $0.1 \%$ Triton X-100 (PTA), suited by incubation in block-PTA (6\% normal goat serum (Sigma-Aldrich, St. Louis, $\mathrm{MO}, \mathrm{USA}$ ) in PTA) overnight. The primary antibodies, polyclonal rabbit anti-serotonin (INCSTAR, Stillwater, MN, USA, dilution 1:500), polyclonal rabbit anti-FMRFamide (Acris Antibodies $\mathrm{GmbH}$, Herford, Germany, dilution 1:500), monoclonal mouse anti-acetylated a-tubulin (Sigma-Aldrich, dilution 1:500), and the monoclonal mouse antibody 22C10 (Developmental Studies Hybridoma Bank, University of lowa, IA, USA, dilution 1:200) were applied for 48-72 hr in block-PTA. Afterwards, specimens were rinsed in block-PTA for $3 \times 2 \mathrm{hr}$ and incubated subsequently with secondary fluorochrome conjugated antibodies (goat anti-rabbit Alexa Fluor 488, Invitrogen, Carlsbad, CA, USA, dilution 1:500; goat anti-mouse Alexa Fluor 568, Invitrogen, dilution 1:500; goat anti-mouse Alexa Fluor 488, Invitrogen, Carlsbad, CA, USA, dilution 1:500) in block-PTA for 24-48 hr. Finally, the specimens were washed 3 times in $0.1 \mathrm{M}$ PBS (without $\mathrm{NaN}_{3}$ ).

The specimens were then mounted in Vectashield mounting medium (Vector Laboratories, Inc.) between 2 glass slides. Negative controls were obtained by omitting the primary antibody in order to check for antibody specificity and yielded no fluorescence signal (data not shown).

\section{Light microscopy, Confocal Microscopy and Image Processing}

Specimens were observed with a confocal laser-scanning microscope Leica TCS STED (Leica Microsystems, Wetzlar, Germany) and a Leica light microscope DM 1000 (Leica Microsystems, Wetzlar, Germany). Confocal image stacks were processed with Leica AS AF v2.3.5 (Leica Microsystems) and Imaris 6.3.1 (Bitplane AG, Zurich, Switzerland). Light microscopic images were processed using the software Leica AS V3.6.0. Final panels were designed using Adobe (San Jose, CA, USA) Photoshop CS3 and Illustrator CS3.

\section{Acknowledgement}

The 22C10 antibody developed by Seymour Benzer (Pasadena, CA) was obtained from the Developmental Studies Hybridoma Bank developed under the auspices of the NICHD and maintained by The University of lowa, Department of Biology, lowa City, IA 52242. We thank the staff of Station Biologique Roscoff for providing facilities and support of sampling animals. Maite Aguado (Madrid) is thanked for commenting on earlier drafts. $\mathrm{CH}$ was supported by special funds of the University of Leipzig and by the EU due to ASSEMBLE grant agreement no. 227799 (http://Www. assemblemarine.org).

\section{References}

ARENDT D, TESSMAR-RAIBLE K, SNYMAN H, DORRESTEIJN A W AND WITTBRODT J (2004). Ciliary photoreceptors with a vertebrate-type opsin in an invertebrate brain. Science 306: 869-871. 
ARENDT D, TESSMAR K, MEDEIROS DE CAMPOS-BAPTISTA M I, DORRESTEIJN A AND WITTBRODT J (2002). Development of pigment-cup eyes in the polychaete Platynereis dumerilii and evolutionary conservation of larval eyes in Bilateria. Development 129: 1143-1154.

ARENDT D AND WITTBRODT J (2001). Reconstructing the eyes of Urbilateria. Phil. Trans $R$ Soc Lond B 356: 1545-1563.

BACKFISCH B, RAJAN V B V, FISCHER R M, LOHS C, ARBOLEDA E, TESSMARRAIBLE K AND RAIBLE F (2013). Stable transgenesis in the marine annelid Platynereis dumerilii sheds new light on photoreceptor evolution. Proc Nat Acad SOC USA 110: 193-198.

BERGTER A, BRUBACHER J L AND PAULULAT A (2008) Muscle formation during embryogenesis of the polychaete Ophryotrocha diadema (Dorvilleidae) - new insights into annelid muscle patterns. Front Zool 5:1.

BERGTER A AND PAULULAT A (2007) Pattern of body-wall muscle differentiation during embryonic development of Enchytraeus coronatus (Annelida: Oligochaeta; Enchytraeidae). J Morphol 268:537-549.

BRINKMANN N AND WANNINGER A (2008) Larval neurogenesis in Sabellaria alveolata reveals plasticity in polycheate neural patterning. Evol Dev 10:606-618.

BRINKMANN N AND WANNINGER A (2010) Integrative analysis of polychaete ontogeny: cell proliferation patterns and myogenesis in trochophore larvae of Sabellaria alveolata. Evol Dev 12:5-15.

BUDAEVA N AND FAUCHALD K (2010). Larval development of Mooreonuphis stigmatis (Treadwell, 1922) (Polychaeta: Onuphidae) from the north-east Pacific. Mar Biol Res 6: 6-24.

CHRISTODOULOU F, RAIBLE F, TOMER R, SIMAKOV O, TRACHANA K, KLAUS S, SNYMAN H, HANNON G J, BORK P AND ARENDT D (2010). Ancient animal microRNAs and the evolution of tissue identity. Nature 463: 1084-1088.

COLLIN, R (2004). Phylogenetic effects, the loss of complex characters, and the evolution of development in calyptraeid gastropods. Evolution 58: 1488-1502.

CONZELMANN M, WILLIAMS E A, TUNARU S, RANDEL N, SHAHIDI R, ASADULINA A, BERGER J, OFFERMANN S AND JÉKELY G (2013). Conserved MIP receptor-ligand pair regulates Platynereis larval settlement. Proc Nat Acad Sci USA 110: 8224-8229.

DORRESTEIJN A (2005). Cell lineage and gene expression in the development of polychaetes. Hydrobiologia 535/536: 1-22.

DRAY N, TESSMAR-RAIBLE K, LE GOUAR M, VIBERT L, CHRISTODOULOU F, SCHIPANY K, GUILLOU A, ZANTKE J, SNYMAN H, BEHAGUE J, VERVOORT $M$, ARENDT D AND BALAVOINE G (2010). Hedgehog signaling regulates segment formation in the annelid Platynereis. Science 329: 339-342.

DROSOPHILA12 GENOMES CONSORTIUM (2007). Evolution of genes and genomes on the Drosophila phylogeny. Nature 450: 203-218.

FISCHERAAND DORRESTEIJN A (2004). The polychaete Platynereis dumerilii (Annelida): a laboratory animal with spiralian cleavage, lifelong segment proliferation and a mixed benthic/pelagic life cycle. BioEssays 26: 314-325.

FISCHER A H, HENRICH T AND ARENDT D (2010). The normal development of Platynereis dumerilii (Nereididae, Annelida). Front Zool 7: 31.

FUJITA S C, ZIPURSKY S L, BENZER S, FERRUS A AND SHOTWELL S L (1982). Monoclonal antibodies against the Drososphila nervous system. Proc Nat Acad Sci USA 79: 7929-7933.

GIBSON G D AND GIBSON A J F (2004). Heterochrony and the evolution of poecilogony: generating larval diversity. Evolution 58: 2704-2717.

GIGA COMMUNITY OF SCIENTISTS (2014). The global invertebrate genomics alliance (GIGA): Developing community resources to study diverse invertebrate genomes. $J$ Hered 105: 1-18.

GOULD S J (1977). Ontogeny and Phylogeny. Belknap Press, Cambridge.

HELM C, SCHEMEL S AND BLEIDORN C (2013). Temporal plasticity in annelid development - ontogeny of Phyllodoce groenlandica (Phyllodocidae, Annelida) reveals heterochronous patterns. J Exp Zool (Mol Dev Evol) 320B: 166-178.

HESSLING R AND WESTHEIDE W (1999) CLSM analysis of development and structure of the central nervous system of Enchytraeus crypticus ("Oligochaeta", Enchytraeidae). Zoomorphology 119:37-47.

HUMMEL T, KRUKKERT K, ROOS J, DAVIS G AND KLÄMBT C (2000). Drosophila Futsch/22C10 is a MAP1B-like protein required for dendritic and axonal development. Neuron 26: 357-370.

JEKELY G, COLOMBELLI J, HAUSEN H, GUY K, STELZER E H K, NEDELEC F
AND ARENDT D (2008). Mechanism of phototaxis in marine zooplankton. Nature 2008 456: 395-399.

KRISTOF A, WOLLESEN T AND WANNINGER A (2008) Segmental mode of neural patterning in Sipuncula. Curr Biol 18:1129-1132.

KRISTOF A, WOLLESEN T, MAIOROVA A S AND WANNINGER A (2011) Cellular and muscular growth patterns during sipunculan development. J Exp Zool (Mol Dev Evol) 316: 227-240.

McDOUGALL C, CHEN W-C, SHIMELD S M AND FERRIER D E K (2006) The development of the larval nervous system, musculature and ciliary bands of Pomatoceros lamarckii (Annelida): heterochrony in polychaetes. Front Zool3:16.

MCEDWARD L R AND JANIES D A (1993). Life cycle evolution in asteroids: What is a larva? Biol Bull 184: 255-268.

MOSS E G (2007). Heterochronic genes and the nature of developmental time. Curr Biol 17: R435-R434.

NIELSEN C (2009). How did indirect development with planktotrophic larvae evolve? Biol Bull 216: 203-215.

ORRHAGE L AND MÜLLER M C M (2005) Morphology of the nervous system of Polychaeta (Annelida). Hydrobiologia 535/536: 79-111.

PAGE L R (2009). Molluscan larvae: pelagic juveniles or slowly metamorphosing larvae? Biol Bull 216: 216-225.

PASQUINELLI A E, REINHAR B, SLACK F, MARTINDALE M Q, KURODA M I, MALLER B, HAYWARD D C, BALL E E, DEGNAN B, MÜLLER P et al. (2000). Conservation of the sequence and temporal expression of let-7 heterochronic regulatory RNA. Nature 408: 86-89.

PASQUINELLI A E AND RUVKUN G (2002). Control of developmental timing by microRNA and their targets. Ann Rev Cell Dev Biol 18: 495-513.

PECHENIK J A (1999). On the advantages and disadvantages of larval stages in benthic marine invertebrate life cycles. Mar Ecol Prog Ser 177: 269-297.

PERNET B AND MCHUGH D (2010). Evolutionary changes in the timing of gut morphogenesis in larvae of the marine annelid Streblospio benedicti. Evol Dev 12: 618-627.

PFANNENSTIEL H D, GRÜNIG C AND LÜCHT J (1987). Gametogenesis and reproduction in Nereid sibling species (Platynereis dumerilii and P. massiliensis). Biol Soc Wash 7: 272-279.

PRUD'HOMME B, DE ROSAR, ARENDTD, JULIEN JF, PAJAZITIR, DORRESTEIJN A W, ADOUTTE A, WITTBRODT J AND BALAVOINE G (2003). Arthropod-like expression patterns of engrailed and wingless in the annelid Platynereis dumerilii suggest a role in segment formation. Curr Biol 2003 13: 1876-1881.

PURSCHKE G (2005). Sense organs in polychaetes (Annelida). Hydrobiologia 535/536: 53-78.

PURSCHKE G, ARENDT D, HAUSEN H AND MÜLLER M C M (2006). Photoreceptor cells and eyes in Annelida. Arthropod Struct Dev 35: 211-230.

RAFF RA (2008). Origins of other metazoan body plans: the evolution of larval forms. Phil Trans R Soc B 363: 1473-1479.

RHODE B (1992). Development and differentiation of the eye in Platynereis dumerilii (Annelida, Polychaeta). J Morphol 212: 71-85.

SCHNEIDER S, FISCHER A AND DORRESTEIJN A W C (1992). A morphometric comparison of dissimilar early development in sibling species of Platynereis (Annelida, Polychaeta). Roux's Arch Dev Biol 201: 243-256.

SCHULZE AAND RICE M E (2009) Musculature in sipunculan worms: ontogeny and ancestral states. Evol Dev 11: 97-108.

SEAVER E, THAMM K AND HILL S D (2005) Growth patterns during segmentation in the two polychaete annelids, Capitella sp. I and Hydroides elegans - comparisons at distinct life history stages. Evol Dev 7: 312-326.

SHARANYAD, THILLAINATHAN B, MARRI S, BOJANALAN, TAYLOR J, FLIBOTTE S, MOERMAN D G, WATERSTON R H AND GUPTA B P (2012). Genetic control of vulval development in Caenorhabditis briggsae. G3 2: 1625-1641.

SIMAKOV O, LARSSON T A AND ARENDT D (2013). Linking micro- and macroevolution at the cell type level: a view from the lophotrochozoan Platynereis dumerilii. Brief Funct Genomics 12: 430-439.

SMITH K K (2003). Time's arrow: heterochrony and the evolution of development. Int J Dev Biol 47: 613-621.

STEINLD, BAOZ, BLASIARD, BLUMENTHALT, BRENTM R, CHEN N, CHINWALLA A, CLARKE L, CLEE C, COGHLAN A, COULSON A et al. (2003). The genome 


\section{C. Helm et al.}

sequence of Caenorhabditis briggsae: A platform for comparative genomics. PLOS Biol 1: e45.

STEINMETZ P R H, KOSTYUCHENKO R P, FISCHER A ARENDT D (2011). The segmental pattern of $o t x, g b x$, and Hox genes in the annelid Platynereis dumerilii. Evol Dev 13: 72-79.

STRUCK T H, PAUL C, HILL N, HARTMANN S, HÖSEL C, KUBE M, LIEB B, MEYER A, TIEDEMANN R, PURSCHKE G AND BLEIDORN C (2011). Phylogenomic analyses unravel annelid evolution. Nature 471: 95-98.

TENNESSEN J M AND THUMMEL C S (2007). Developmental timing: let-7 function conserved through evolution. Curr Biol 18: R707-R708.

TESSMAR-RAIBLE K AND ARENDT D (2003). Emerging systems: between vertebrates and arthropods, the Lophotrochozoa. Curr Opin Genet Dev 13: 331-340.

TESSMAR-RAIBLE K, RAIBLE F, GUY K, REMBOLD M, HAUSEN H AND ARENDT D (2007). Evolution of the vertebrate hypothalamus: An ancient set of sensoryneurosecretory cell types in the polychaete and vertebrate medial forebrain. Cell 129: $1389-1400$.

TOMER R, DENES A S, TESSMAR-RAIBLE K AND ARENDT D (2010). Profiling by image registration reveals common origin of annelid mushroom bodies and vertebrate pallium. Cell 142: 800-809.

VEEDIN-RAJAN V B, FISCHER R M, RAIBLE F AND TESSMAR-RAIBLE K (2013).
Conditional and specific cell ablation in the marine annelid Platynereis dumerilii. PLOS ONE 8: e75811.

VORONEZHSKAYA E E, TSITRIN E B AND NEZLIN L P (2003) Neuronal development in larval polychaete Phyllodoce maculata (Phyllodocidae). J Comp Neurol 455:299-309.

WANNINGER A (2009) Shaping the Things to Come: Ontogeny of lophotrochozoan neuromuscular systems and the tetraneuralia concept. Biol Bull 216:293-306.

WANNINGER A, KOOP D, BROMHAM L, NOONAN E AND DEGNAN B M (2005) Nervous and muscle system development in Phascolion strombus (Sipuncula). Dev Genes Evol 215:509-518.

WEIGERT A, HELM C, MEYER M, NICKEL B, ARENDT D, HAUSDORF B, SANTOS S R, HALANYCH K M, PURSCHKE G, BLEIDORN C AND STRUCK T H (2014) Illuminating the base of the annelid tree using transcriptomics. Mol Biol Evol 31: 1391-1401.

WINCHELLCJ, VALENCIAJEAND JACOBSDK(2010). Confocal analysis of nervous system architecture in direct-developing juveniles of Neanthes arenaceodentata (Annelida, Nereididae). Front Zool 7: 17.

YAMAGUCHI E AND SEAVER C S (2013). The importance of larval eyes in the polychaete Capitella teleta: effects of larval eye deletion on formation of the adult eye. Invert Biol 132: 352-367. 


\section{Further Related Reading, published previously in the Int. J. Dev. Biol.}

rachyury, Tbx2/3 and sall expression during embryogenesis of the indirectly developing polychaete Hydroides elegans Cesar Arenas-Mena

Int. J. Dev. Biol. (2013) 57: 73-83

http://dx.doi.org/10.1387/ijdb.120056ca

Stable expression of Y-box protein 1 gene in early development of the abalone Haliotis diversicolor Jun Chen, Zhi-Sen Chen, Zi-Xia Huang, Cai-Huan Ke, Jie Zhang, Yi-Xiang Zhong, Wei-Wei You and Jing Zhao Int. J. Dev. Biol. (2012) 56: 369-375 http://dx.doi.org/10.1387/ijdb.113487zc

Planarian embryology in the era of comparative developmental biology José M. Martín-Durán, Francisco Monjo and Rafael Romero Int. J. Dev. Biol. (2012) 56: 39-48 http://dx.doi.org/10.1387/ijdb.113442jm

Evolutionary history of the Tricladida and the Platyhelminthes: an up-to-date phylogenetic and systematic account Marta Riutort, Marta Álvarez-Presas, Eva Lázaro, Eduard Solà and Jordi Paps Int. J. Dev. Biol. (2012) 56: 5-17 http://dx.doi.org/10.1387/ijdb.113441mr

Functional analysis of grimp, a novel gene required for mesodermal cell proliferation at an initial stage of regeneration in Enchytraeus japonensis (Enchytraeidae, Oligochaete)

Makoto Takeo, Chikako Yoshida-Noro and Shin Tochinai

Int. J. Dev. Biol. (2010) 54: 151-160

http://dx.doi.org/10.1387/ijdb.082790mt

Differences in embryonic pattern formation between Caenorhabditis elegans and its close parthenogenetic relative Diploscapter coronatus

Vera Lahl, Jens Schulze and Einhard Schierenberg

Int. J. Dev. Biol. (2009) 53: 507-515

http://dx.doi.org/10.1387/ijdb.082718vl

Serotonin involvement in the metamorphosis of the hydroid Eudendrium racemosum

Giuliana Zega, Roberta Pennati, Arianna Fanzago and Fiorenza De Bernardi Int. J. Dev. Biol. (2007) 51: 307-313

http://dx.doi.org/10.1387/ijdb.062195gz

5 yr ISI Impact Factor $(2011)=2.959$
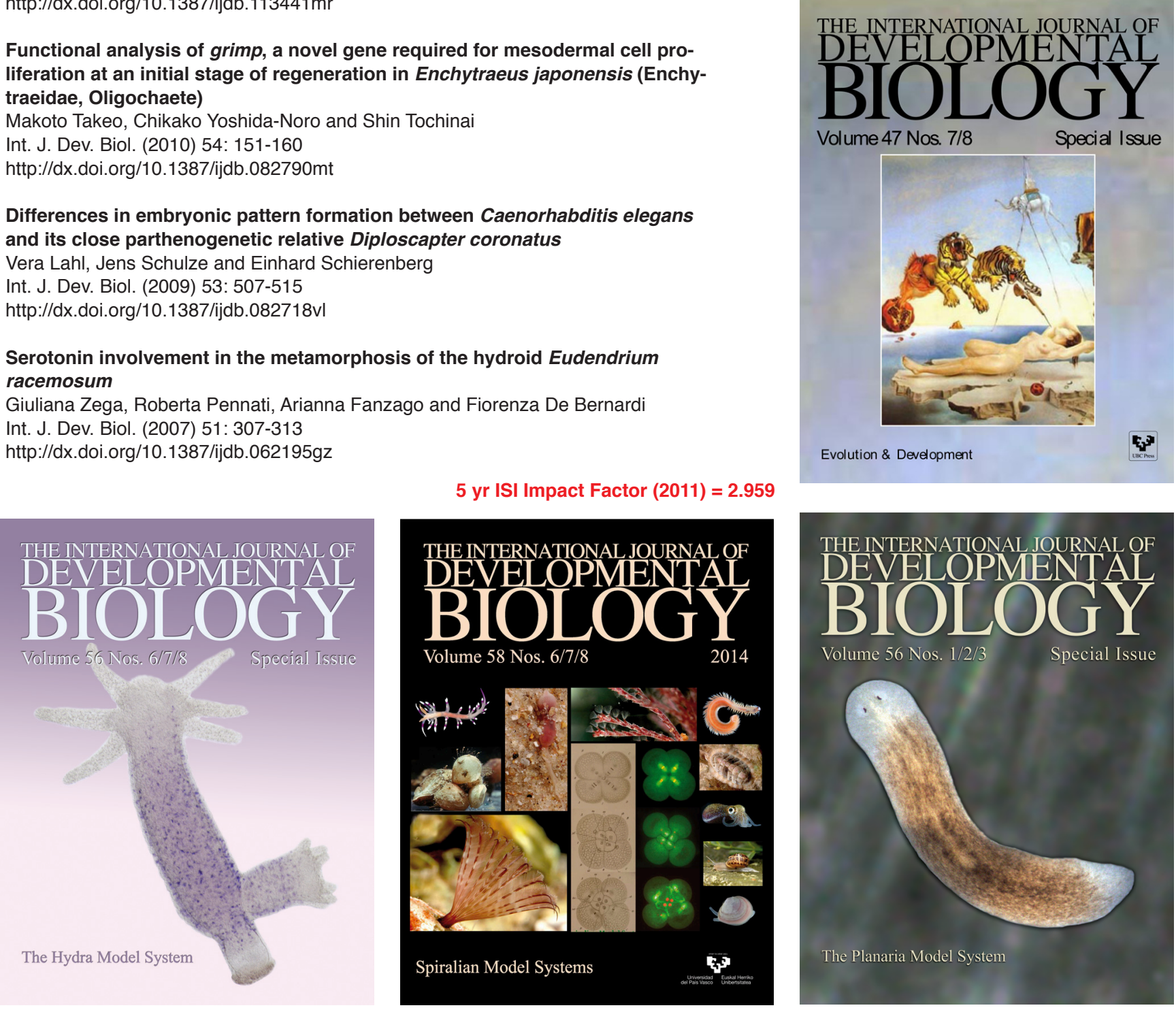